\title{
Prostate cancer survival in sub-Saharan Africa by age, stage at diagnosis, and human development index: a population-based registry study
}

\author{
Tobias P. Seraphin ${ }^{1}$ - Walburga Y. Joko-Fru ${ }^{2,3}$. Shyam S. Manraj ${ }^{4}$ - Eric Chokunonga ${ }^{5} \cdot$ Nontuthuzelo I. M. Somdyala $^{6}$. \\ Anne Korir ${ }^{7}$. Guy N'Da ${ }^{8,9}$. Anne Finesse ${ }^{10} \cdot$ Henry Wabinga $^{11}$. Mathewos Assefa ${ }^{12}$. Freddy Gnangnon ${ }^{13}$. \\ Rolf Hansen $^{14}$ - Nathan G. Buziba ${ }^{15}$ - Biying Liu² - Eva J. Kantelhardt ${ }^{1,16}$ (D) Donald M. Parkin ${ }^{3,17}$
}

Received: 7 February 2021 / Accepted: 25 May 2021 / Published online: 10 July 2021

(c) The Author(s) 2021

\begin{abstract}
Objectives To estimate observed and relative survival of prostate cancer patients in sub-Saharan Africa (SSA) and to examine the influence of age, stage at diagnosis and the Human Development Index (HDI).

Patients and methods In this comparative registry study, we selected a random sample of 1752 incident cases of malign prostatic neoplasm from 12 population-based cancer registries from 10 SSA countries, registered between 2005 and 2015. We analyzed the data using Kaplan-Meier and Ederer II methods to obtain outcome estimates and flexible Poisson regression modeling to calculate the excess hazards of death

Results For the 1406 patients included in the survival analyses, 763 deaths occurred during 3614 person-years of observation. Of patients with known stage, $45.2 \%$ had stage IV disease, $31.2 \%$ stage III and only $23.6 \%$ stage I and II. The 1 and 5-year relative survival for the entire cohort was 78.0\% (75.4-80.7) and 60.0\% (55.7-64.6), while varying between the registries. Late presentation was associated with increased excess hazards and a 0.1 increase in the HDI was associated with a $20 \%$ lower excess hazard of death, while for age at diagnosis no association was found.

Conclusions We found poor survival of SSA prostatic tumor patients, as well as high proportions of late stage presentation, which are associated with inferior outcome. This calls for investment in health-care systems and action regarding projects to raise awareness among the population to achieve earlier diagnosis and improve survival.
\end{abstract}

Keywords Adenocarcinoma of the prostate $\cdot$ Population-based cancer registration $\cdot$ Africa $\cdot$ Survival $\cdot$ Cancer surveillance

Eva J. Kantelhardt

eva.kantelhardt@uk-halle.de

1 Institute of Medical Epidemiology, Biostatistics, Biometrics and Informatics, Martin-Luther-University Halle-Wittenberg, Magdeburgerstrasse 8, 06097 Halle (Saale), Germany

2 African Cancer Registry Network, INCTR African Registry Programme, Oxford, UK

3 Nuffield Department of Population Health, University of Oxford, Oxford, UK

4 Mauritius National Cancer Registry, Candos, Mauritius

5 Zimbabwe National Cancer Registry, Harare, Zimbabwe

6 Eastern Cape Cancer Registry, South African Medical Research Council, Tygerberg, South Africa

7 National Cancer Registry, Kenya Medical Research Institute, Nairobi, Kenya

8 Registre Des Cancers d'Abidjan, Abidjan, Côte d'Ivoire
9 Université Mohammed V de Rabat, Rabat, Morocco

10 Seychelles National Cancer Registry, Victoria, Seychelles

11 Kampala Cancer Registry, Makerere University School of Medicine, Kampala, Uganda

12 Addis Ababa City Cancer Registry, Addis Ababa University, Addis Ababa, Ethiopia

13 Cotonou Cancer Registry, Ministry of Health, Cotonou, Republic of Benin

14 Namibian National Cancer Registry, Cancer Association of Namibia, Windhoek, Namibia

15 Eldoret Cancer Registry, Moi University, Eldoret, Kenya

16 Department of Gynaecology, University Hospital Halle, Martin-Luther-University Halle-Wittenberg, Halle, Germany

17 International Agency for Research on Cancer, Lyon, France 


\section{Introduction}

According to GLOBOCAN estimates for the year 2018, prostate cancer was the top cancer in terms of age-standardized incidence rates in males in the majority of countries (118) worldwide and in nearly all of those in sub-Saharan African (SSA) (42) [1]. It is predicted, that just through demographic changes, the annual number of incident prostate cancer cases in Africa will more than double during the next 20 years [2]. In a recent analysis of time trends in prostate cancer incidence in sub-Saharan Africa, we showed that even adjusted for the effect of demographic changes the rates have been increasing annually by $2-10 \%$ during the last decade [3]. With a growth rate of $2 \%$ throughout the next two decades, the number of cases of prostate cancer will have more than tripled by 2040 [2]. Already today SSA countries are struggling to deal with the burden of cancer. Late presentation of prostate cancer patients has been described in several hospital-based studies while difficulties in access to adequate care of cancer patients in general is a well-known problem of SSA [4-9]. Although prostate cancer is estimated to be the number one cancer in terms of both numbers of cases and deaths in males in most SSA countries [1], there is little information on survival. The few hospital-based studies available have reported wide variations, but mainly poor survival from prostate cancer in SSA $[8,10,11]$, yet those estimates have limited generalizability to the general population of the region. Population-based cancer registries originally simply monitored the occurrence of incident cancers, however "the activities of cancer registries have developed far beyond this to include studies of cancer cause and prevention, and to provide the information needed for the planning and evaluation of cancer-control programmes" [12].

Since 2012 the African Cancer Registry Network (AFCRN) has been the partner of the International Agency for Research on Cancer (IARC), facilitating populationbased cancer registration in SSA as a regional hub of the Global Initiative for Cancer Registration (GICR) [13]. Data on survival from prostate cancer have been published from individual registries [14-17]. However, a broad and in depth analysis of the population-based survival of prostate cancer patients in SSA and an analysis of influencing factors is not available.
In this comparative registry study, we estimate 1-, 3- and 5 -year observed and relative survival for 12 populationbased cancer registries from 10 SSA countries and examine the influence of age, stage at diagnosis, and the Human Development Index [18].

\section{Patients and methods}

\section{Study population}

We obtained data from 12 population-based cancer registries from 10 SSA countries, all members of the African Cancer Registry Network (AFCRN, https://afcrn.org/): Cotonou (Benin), Abidjan (Côte d'Ivoire), Addis Ababa (Ethiopia), Eldoret (Kenya), Nairobi (Kenya), Mauritius, Namibia, Eastern Cape (South Africa), Seychelles, Kampala (Uganda), Bulawayo (Zimbabwe) and Harare (Zimbabwe). In 2016 we invited those registries that were members of AFCRN that were capable of providing follow-up data for a minimum of 3 years, and ideally 5 and the aforementioned agreed to participate. From each individual registry, we took a simple random sample from lists of incident prostate cancer cases (ICD-O-10: C61) in the AFCRN database, registered between 2005 and 2015. For Harare (Zimbabwe) we took one random sample of cases among black men and one of white men from the same period. Since active follow-up is resource intensive in this setting, the sample size for each registry was determined by the feasibility of obtaining follow-up information. If passive follow-up was used, a larger number of patients could be included.

Primary prostate cancer cases of at least 15 years of age were eligible for sampling. Recurrences and cases registered on the basis of a death certificate only (DCO) were excluded. We measured the follow-up time from the date of incidence to the date of last contact alive, to the date of death or to the closing date of the study for the corresponding registry, whichever occurred first.

Cases were excluded from survival analyses due to the following criteria: (1) Less than one day of follow-up time; (2) incoherent dates (i.e. the registered date of incidence lies after the date of last contact); (3) double registrations; (4) found not to be prostate cancer during the follow-up 
process; (5) initially diagnosed before the study period of the registry (registered relapses); (6) unknown age.

\section{Covariates}

\section{Vital status}

We investigated vital status using means of active and passive follow-up. All registries, apart from Mauritius used active follow-up methods. In Mauritius, the follow-up was done passively, by linking the records to the death registry. In 2012, the completeness of this death registry was estimated to be $100 \%$ [19]. For verification, the registry performed active follow-up of $10 \%$ of the presumably living patients and found all of this $10 \%$ sample to be still alive on 31st December 2013. Accordingly, we assumed patients to be still alive, if they were not registered in the death registry.

In all other registries, active follow-up was performed, using medical records to determine the patient's vital status and date of last contact. For patients not known to have died, the registry staff augmented this information, if possible, with phone calls and sometimes home visits to the patients and their relatives. We censored patients "alive" at the date of last contact, if vital status (alive or dead) was unknown at the closing date (Appendix Fig. 3).

\section{Stage at diagnosis}

At the time of registration, the registry staff abstracted information on clinical stage at diagnosis. For most registries this included tumor-node metastasis (TNM) assessment. For some registries additional information was available on prostate specific antigen (PSA) levels at time of diagnosis and/ or the Gleason Score. We used the AJCC Cancer Staging Manual 8th edition, of the American Joint Cancer Committee (AJCC) [20] to classify each prostate cancer case to one of the four stage groups (I-IV). Since for some patients only PSA level and/or Gleason score was available, a stage was assigned on the basis of this information alone, assuming the other risk factors to be at minimum level. Accordingly, we grouped all prostate cancer cases in one of the following groups: "Stage I-II", "Stage III, "Stage IV" and "Stage unknown". For the registries of Mauritius and Eastern Cape (South Africa) no stage information was available.

\section{Basis of diagnosis}

The registries code the most valid basis of diagnosis [21] they can find for each cancer patient. We grouped "Morphologically verified" cases as those with histopathological verification of the primary tumor (the majority), and a few cases with cytological diagnosis or histopathological verification of metastases.

\section{Human development index}

According to the United Nations Development Programme (UNDP), the Human Development Index (HDI) is a "composite index measuring average achievement in three basic dimensions of human development-a long and healthy life, knowledge and a decent standard of living" [22]. The HDI "is perhaps the most popular index used to assess countries' well-being levels across the globe" [18]. For those registries covering sub-national populations, we used the more precise Sub-national Human Development Index (SHDI) (https:// globaldatalab.org/) [18] to allow for the wide differences of well-being within countries in SSA. For Namibia, where registry coverage is not complete at the national level, we estimated a weighted average HDI, based on the SHDI of the 13 regions of the country and the number of cases from each in the random sample. In order to compare between the registries, the HDI value of 2013 was chosen.

\section{Statistical analyses}

\section{Observed survival}

Following exclusion of ineligible cases (as described above), we estimated observed survival (OS) probabilities at 1, 3 and 5 years of follow-up, applying the semi-complete [23] approach. We plotted Kaplan-Meier (KM) curves of observed survival probabilities, as well as observed survival stratified by HDI group, age and stage group at diagnosis.

We used R, Version 3.6.3 [24] in the integrated development environment RStudio, Version 1.2.5033 [25] with the packages "survival" [26] and "survminer" [27]. 
The percentage of cases with morphological diagnosis (MV\%) was calculated as an indicator of data quality [28]. We estimated the median follow-up time for all cases, including those with a known event of death.

\section{Relative survival}

To adjust for mortality due to causes of death other than prostate cancer, we calculated crude and age-standardized Ederer II relative survival (RS) at 1, 3 and 5 years of followup, using the "relsurv" package [29] for R. We obtained the national life tables as five-year age-specific death rates by calendar year, sex and country from the WHO Mortality database [30] and expanded them using a Poisson regression model implemented in the "rcsgen" [31] command for STATA 15 , to obtain complete life tables by one year age group (more information in the Supplement). We performed direct age-standardization by applying the age-specific weights of the International Cancer Survival Standard-1 for prostate cancer [32], but, since the numbers of subjects in the upper and lower age groups of the standard were very small, when stratifying by registry, we used just three broad age groups: $15-64,65-74,75-99$.

\section{Estimation of average survival}

We estimated average 5-year survival for the ten countries under observation, adjusting for the different size of the datasets from each country, using the method of AbdelRahman et al. [33]. In brief: we weighted the mean of the 5 -year survival from each country by the number of prostate cancer patients included as a proportion of the total cases for that country, as estimated by GLOBOCAN 2018 [1]. This does not necessarily imply that regional survival estimates can be extrapolated to the national level.

\section{Assessing loss to follow-up}

We assessed the proportions of patients lost to follow-up (LFU) at 1, 3 and 5 years. Since these proportions were above $10 \%$, and in such cases it is desirable to investigate if censoring is at random, we performed an "inverse" Cox proportional hazards model with LFU as the outcome and adjusted for age and stage at diagnosis for year 1 and year 5 .

\section{Assessing the potential of 5-year follow-up}

For all registries (except Mauritius) the closing date for follow up was 31st December, 2017, so that we calculated the potential follow up period for each patient as the difference between the date of incidence and the closing date. If this period was greater than 5 years, we considered this patient to have a potential of 5-year follow-up.

\section{Modeling excess hazards}

We used univariable and multivariable Poisson regression models adjusted for stage group, HDI as a continuous variable and age group at diagnosis, splitting time into monthly intervals and using restricted cubic splines, to model excess hazards of death in RS framework for prostate cancer patients [34].

\section{Results}

Mauritius, Namibia and Seychelles had national population coverage, the registry in Eastern Cape (South Africa) covers a rural area and all other registries cover urban areas. From these 12 population-based cancer registries a total 1752 cases were randomly selected, representing a $44 \%$ of the total prostate cancer cases (after exclusion of death certificate only cases) registered within the study period (Table 1).

Table 1 shows, for each registry, the total number of prostate cancer patients from the catchment area during study period, the number (and \%) of DCO cases (not eligible for the study sample), and the number of cases in the random sample (and sampling fraction). Also shown is the number (and percentage) of the cases in the random sample included for survival analysis, following exclusion on non-eligible cases, as described above, their mean age and the percentage of morphologically verified (MV) cases.

The sampling fraction ranged from $18 \%$ in Namibia, to $100 \%$ in six registries. The proportion of MV cases ranged from $42 \%$ in Kampala (Uganda) to $96 \%$ in Mauritius. Following exclusions, 1406 prostate cancer patients were included in the survival analysis, representing $80 \%$ of our random sample. During a total of 3613 person-years of observation, there were 763 deaths, and the individual 
Table 1 Total number of prostate cancer cases registered, included and excluded, data quality indicator by population-based cancer registry

\begin{tabular}{|c|c|c|c|c|c|c|c|c|}
\hline Country & Registry & HDI in $2013^{1}$ & $\begin{array}{l}\text { Period of diag- } \\
\text { nosis }\end{array}$ & $\begin{array}{l}\text { Total of prostate } \\
\text { cancer patients } \\
\text { during study } \\
\text { period }\end{array}$ & $\begin{array}{l}\text { No. excluded } \\
\text { due to DCO } \\
(\%)\end{array}$ & $\begin{array}{l}\text { Random sample, } \\
\text { (sampling frac- } \\
\text { tion \%) }\end{array}$ & $\begin{array}{l}\text { Included for } \\
\text { survival analy- } \\
\text { ses, (fraction of } \\
\text { random sample, } \\
\% \text { ) }\end{array}$ & MV, $\%$ \\
\hline Benin & Cotonou & 0.580 & 2013-2014 & 54 & $0(0)$ & $54(100)$ & $43(80)$ & 53 \\
\hline Côte d'Ivoire & Abidjan & 0.548 & 2013-2014 & 286 & $0(0)$ & $160(56)$ & $127(79)$ & 65 \\
\hline Ethiopia & Addis Ababa & 0.653 & 2012 & 49 & $0(0)$ & 49 (100) & $45(92)$ & 73 \\
\hline \multirow[t]{2}{*}{ Kenya } & Eldoret & 0.546 & 2009-2013 & 177 & $7(4)$ & $75(44)$ & $23(31)$ & 74 \\
\hline & Nairobi & 0.622 & 2009-2013 & 866 & $47(5)$ & 149 (18) & $134(90)$ & 75 \\
\hline Mauritius & Mauritius & 0.775 & 2005-2009 & 340 & $9(3)$ & $331(100)$ & $326(99)$ & 96 \\
\hline Namibia & Namibia & $0.665^{2}$ & 2012-2013 & 443 & $0(0)$ & $80(18)$ & $35(44)$ & 74 \\
\hline Seychelles & Seychelles & 0.782 & 2008-2013 & 140 & $10(7)$ & $130(100)$ & $119(92)$ & 95 \\
\hline South Africa & Eastern Cape & 0.644 & 2008-2013 & 260 & $0(0)$ & $260(100)$ & 201 (77) & 49 \\
\hline Uganda & Kampala & 0.621 & 2009-2013 & 559 & $5(1)$ & $150(27)$ & $114(76)$ & 42 \\
\hline \multirow[t]{3}{*}{ Zimbabwe } & Bulawayo & 0.623 & 2012-2013 & 135 & $21(16)$ & $60(53)$ & $50(83)$ & 54 \\
\hline & Harare (black) & 0.599 & 2009-2013 & 905 & $168(19)$ & $200(27)$ & $148(74)$ & 91 \\
\hline & Harare (white) & 0.599 & 2009-2013 & 66 & $12(18)$ & $54(100)$ & $41(76)$ & 93 \\
\hline Total & & & $2005-2014$ & 4280 & $279(7)$ & $1752(44)$ & $1406(80)$ & 75 \\
\hline
\end{tabular}

$D C O$ death certificate only, $M V$ morphologically verified

${ }^{1}$ Human Development Index (http://hdr.undp.org/en/data and https://globaldatalab.org/), Levels Very High HDI (0.800-1.000), High HDI (0.700-0.799), Medium HDI (0.550-0.699), Low HDI (0.000-0.549)

${ }^{2}$ National weighted average (by No. of cases per subregion) of the subnational HDIs (https://globaldatalab.org/)

median time of follow-up was 1.78 years (Table 2), without excluding the deaths from the calculation. The HDI ranged from 0.546 in Eldoret (Kenya) to 0.782 in Seychelles.

The mean (SD) age at diagnosis was 70.5 (9.7) years, and ranged from 66.5 (9.1) years in Namibia, to 74.2 (9.8) in Eldoret (Kenya) (Table 2). Distribution of age by registry can be seen in Appendix Fig. 4. Age distribution of our cohort was compared with that of all prostate cancer cases in the target populations during the years concerned, and found to be representative. Information on stage was only available for $40.5 \%$ of patients from the 10 registries contributing staging information (i.e. excluding Mauritius and Eastern Cape, South Africa). Of patients with a known stage, $45.2 \%$ had stage IV disease, $31.2 \%$ stage III and only $23.6 \%$ stage I and II. The proportion of "Stage unknown" varied widely between the registries and ranged from $17 \%$ in Namibia, to $76 \%$ and $75 \%$ in the cohort of white and black men in Harare (Zimbabwe), respectively. The highest proportion of Stage I and Stage II disease was found in Namibia, Seychelles and Nairobi (Kenya), with 31\%, 21\% and 13\%, respectively (Appendix Fig. 5).

\section{Assessing Loss to follow-up}

LFU was the highest during the first year; for the entire cohort it was $13 \%$. The proportion of LFU in the first year ranged from 0 and $2 \%$ in Seychelles and Harare (Zimbabwe) blacks, to 49 and 36\% in Cotonou (Benin) and Abidjan (Côte d'Ivoire). Our Cox model, adjusted for stage and age group, showed that censoring was at random at year one, as well as during the whole study period.

The registry cohorts from Cotonou (Benin) and Bulawayo (Zimbabwe) had no potential for a 5-year follow-up. Since only three patients from Addis Ababa had a potential of 5-year follow-up, we did not estimate 5-year survival for this registry. Nairobi (Kenya) had the lowest percentage of cases with a complete 5-year follow-up (51\%), whereas Mauritius 


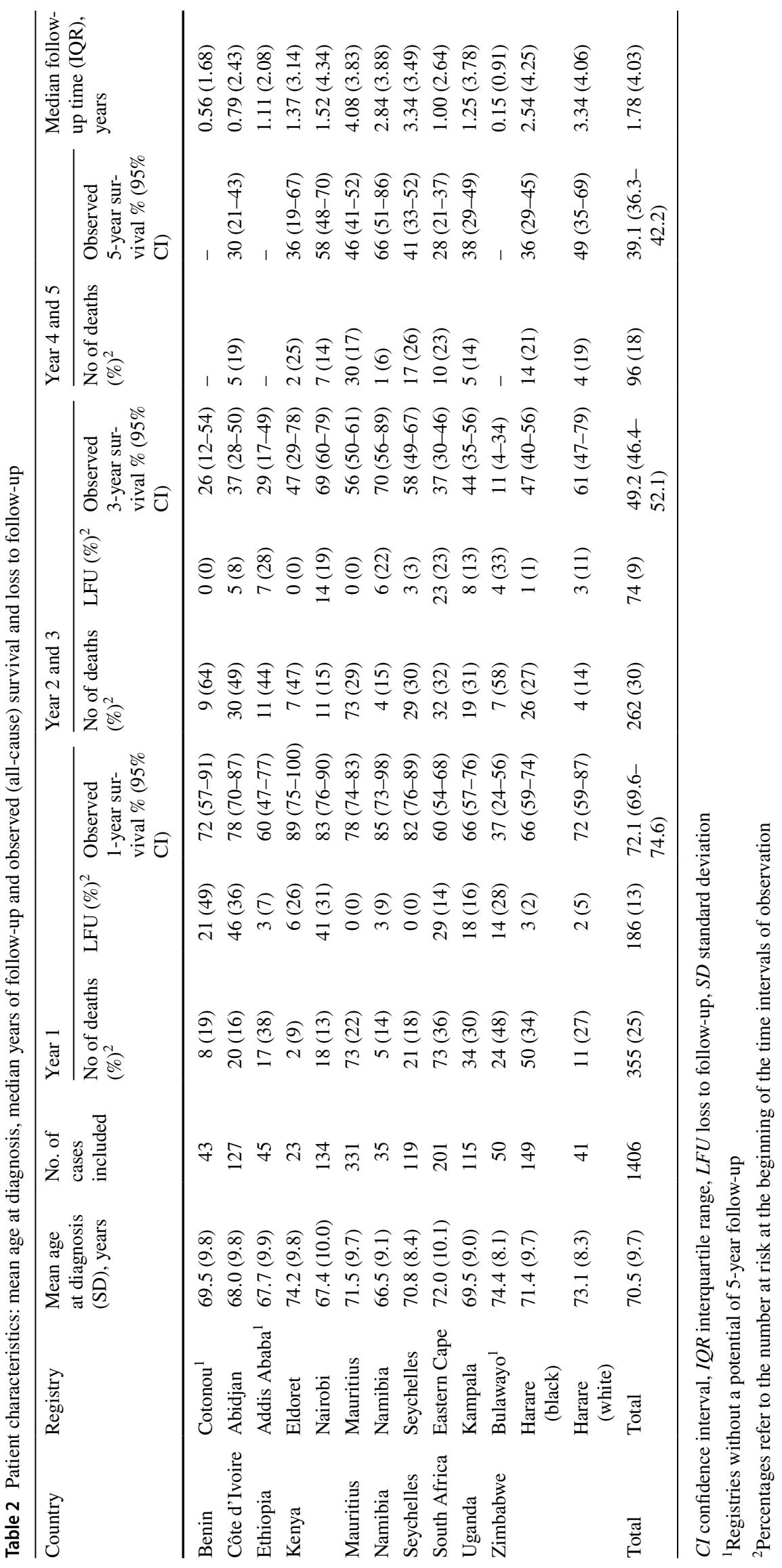


and blacks from Harare (Zimbabwe) had the highest with $100 \%$ and $96 \%$, respectively (Appendix Table 4).

\section{Survival statistics for all ages by registry}

For the whole study cohort, the observed Kaplan-Meier survival probability $(95 \% \mathrm{CI}$ ) for prostate cancer patients was $72.1 \%(69.6-74.6)$ at year one, $49.2 \%(46.4-52.1)$ at year 3 and $39.1 \%(36.3-42.2)$ at year 5 (Fig. 1A, Table 2). The youngest age group had the highest observed survival (Fig. 1B). The 5-year observed survival probability was highest in Namibia and lowest in Eastern Cape (South Africa) (Table 2, Appendix Fig. 6).

The 1-, 3- and 5-year relative survival for the entire cohort was 78.0\% (75.4-80.7), 62.9\% (59.4-66.7) and 60.0\% (55.7-64.6) (Appendix Fig. 7). The values varied by registry, with the highest values of 5-year relative survival found in
Namibia, Nairobi (Kenya), in whites of Harare (Zimbabwe) and in Eldoret (Kenya). The lowest values of 5-year relative survival were found in Eastern Cape (South Africa) and in Kampala (Uganda).

Figure 2 shows the 1-, 3- and 5-year age-standardized relative survival (ASRS) in the different registries. At year 5 we found the highest values for Nairobi (Kenya) and white patients in Harare (Zimbabwe) and the lowest values for Eastern Cape (South Africa). The ASRS also varied within countries. E.g. in Zimbabwe at year 1, where the cohorts from the capital Harare had a better outcome than the cohort from Bulawayo. The ASRS also varied between the white and the black patients from Harare (Zimbabwe), with the whites having one of the best ASRS after 5 years and the blacks having one of the poorest. The ten countries under observation had an estimated average relative survival (taking into account the different sample sizes from each

\section{(B)} Observed survival by age group (years) Age group: $-30-64-65-74-\geq 75$

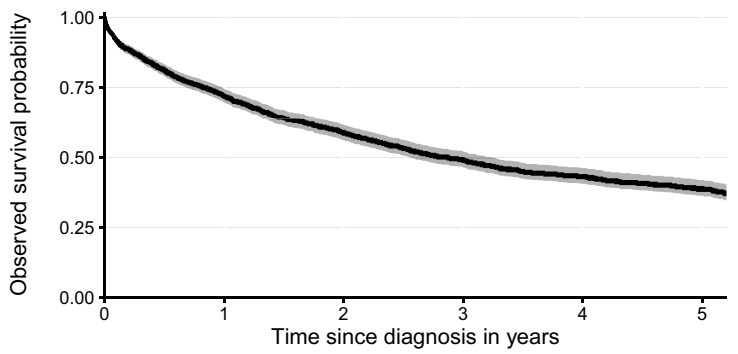

Number at risk

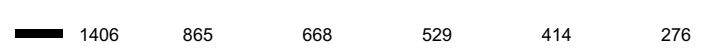

(C) Observed survival by stage ${ }^{1}$

Stage: - Stage I+II - Stage III - Stage IV - Stage unknown
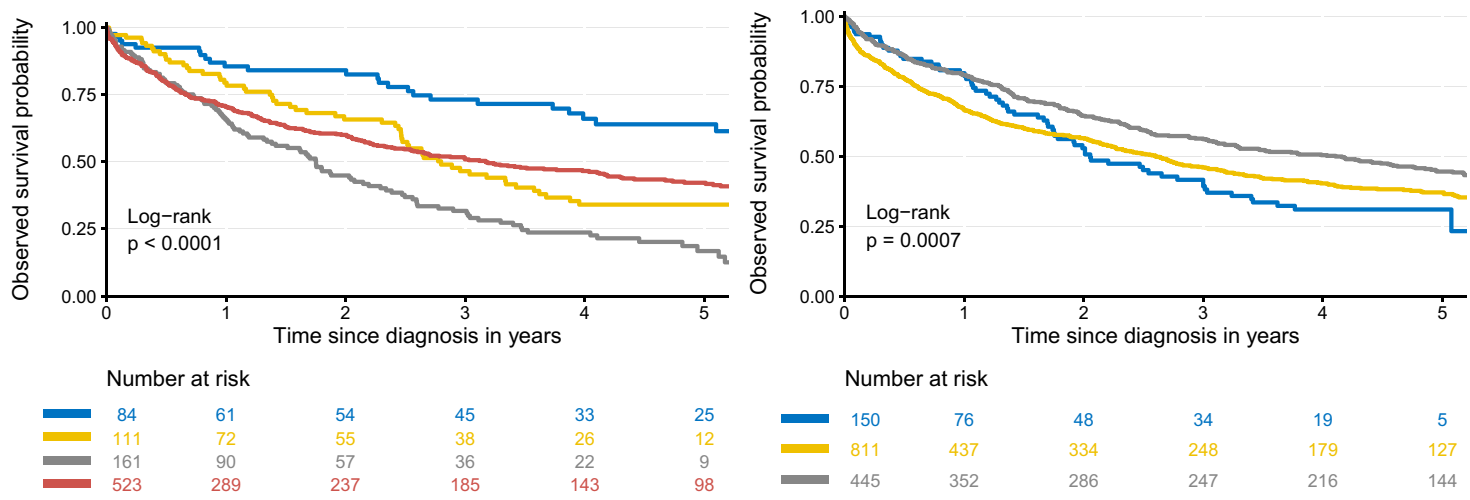

Fig. 1 Observed (all-cause) survival for the entire study cohort (A), by age group (B), by stage (C), and Human Development Index (HDI) (D), Source HDI (http://hdr.undp.org/en/data and
${ }^{1}$ Mauritius and Eastern Cape (South Africa) excluded, since no staging information was available http://globaldatalab.org/). 


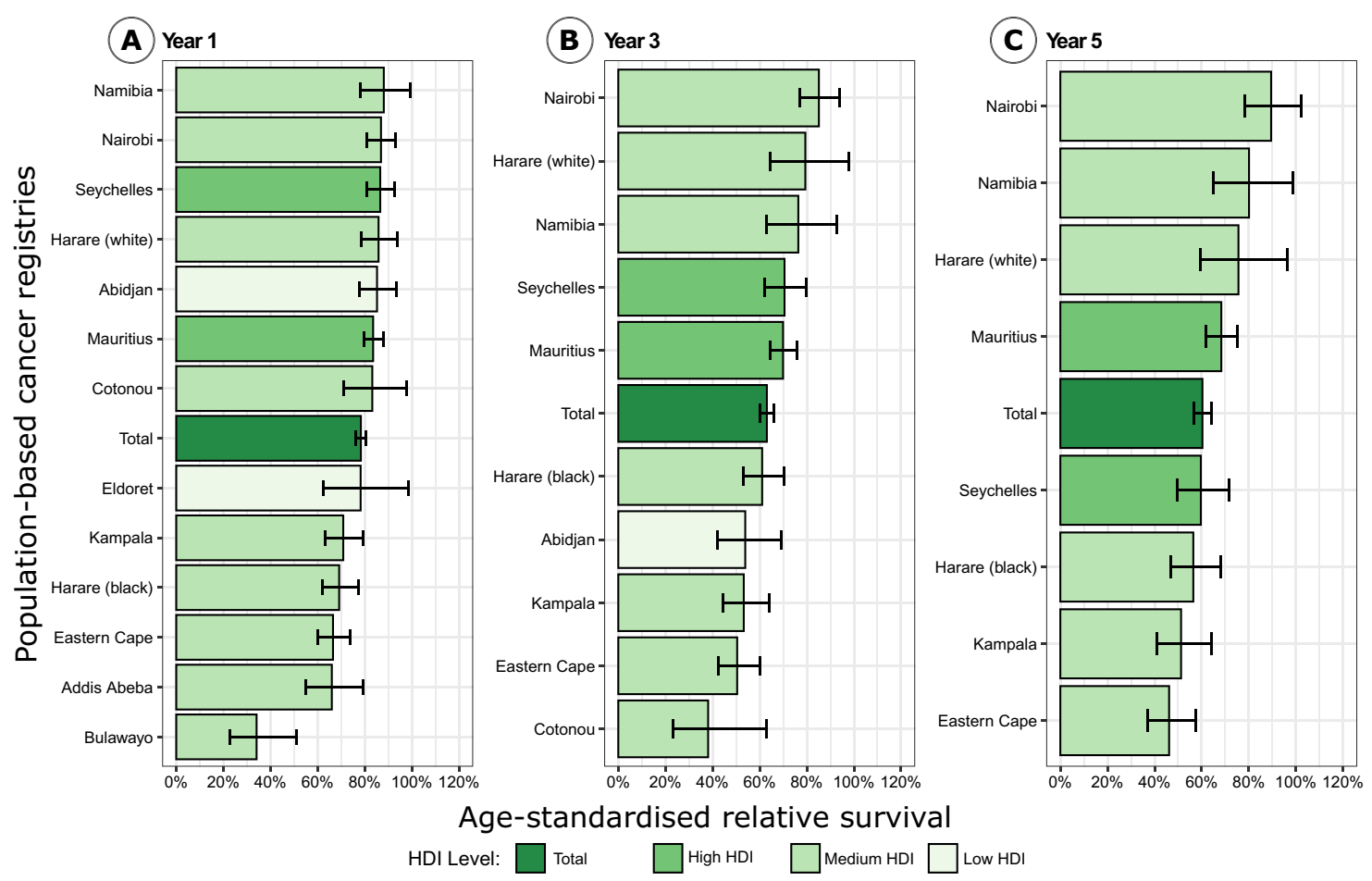

Fig. 2 Comparison of 1- (A), 3- (B) and 5-year (C) age-standardized relative survival with 95\% confidence intervals (CI) by registry and Human Development Index (HDI)

country) of $73.1 \%(62.5-85.9)$ at year $1,49.7 \%(36.9-69.0)$ at year 3 and 55.3 (42.1-73.2) at year 5. However, this sample was mainly from urban populations and is not representative for the whole of SSA.

\section{Survival by age at diagnosis and registry}

The oldest age group ( $>=75)$ had a significantly better relative survival probability than both younger groups $(<65$, 65-74) with 5-year RS point estimates (95\% CI) of 74.9\% (65.3-85.9), 56.1\%(49.8-63.2) and 51.8\% (45.7-58.7), respectively (Appendix Table 5). For most registries we observed the highest relative survival point estimates in the oldest age group at all three evaluated time points. This was not the case for Addis Ababa (Ethiopia) and Namibia, where the highest values were found in the younger age groups.

\section{Survival by stage at diagnosis}

We observed differing KM survival by stage at diagnosis for the entire cohort (Mauritius and Eastern Cape (South Africa) excluded). At five years, those with Stage I + II disease (64.0\% [53.1-77.0]) had significantly higher point estimates than those with Stage III (34.1\% [25.3-45.9]) and
Stage IV disease (16.8\% [10.7-26.3]) (Fig. 1C). This pattern was also observed in relative survival estimates for the entire cohort and within registries. The relative survival in each stage group, varied between the registries yet the confidence intervals were mainly wide and overlapping (Appendix Table 6).

\section{Excess hazard ratio}

Stage III and Stage IV at diagnosis were associated with a three- and sevenfold risk of death compared to Stage I+ II at diagnosis (Table 3). When adjusting for age at diagnosis and HDI, we observed a similar independent association. An increase of the HDI by one decimal point (0.1) decreased the risk of death by $20 \%$ (95\% CI: 9-30\%) in our model, adjusted for age and stage at diagnosis. Age at diagnosis was not associated with the hazard of death in either the univariable or in the adjusted model. We did not find any evidence in our models for an interaction between age and stage at diagnosis.

\section{Discussion}

This comparative analysis - to our knowledge, the first of its kind from sub-Saharan Africa-evaluates the survival of prostate cancer patients from 10 different countries, 
Table 3 Prostate cancer excess mortality hazard by age and stage at diagnosis and HDI

\begin{tabular}{|c|c|c|c|c|c|}
\hline & \multirow[t]{2}{*}{ No. of cases } & \multicolumn{2}{|l|}{ Univariable analysis } & \multicolumn{2}{|l|}{ Multivariable model $^{1}$} \\
\hline & & Excess hazard ratio $(95 \% \mathrm{CI})$ & $p$ Value & Excess hazard ratio $(95 \% \mathrm{CI})$ & $p$ Value \\
\hline \multicolumn{6}{|c|}{ Age at diagnosis (years) } \\
\hline$<65$ & 364 & Reference & & Reference & \\
\hline $65-74$ & 525 & $1.17(0.91-1.51)$ & 0.213 & $1.19(0.93-1.53)$ & 0.173 \\
\hline $75+$ & 517 & $0.85(0.63-1.14)$ & 0.281 & $0.92(0.68-1.24)$ & 0.584 \\
\hline \multicolumn{6}{|l|}{ Stage at diagnosis } \\
\hline Stage I+ II & 84 & Reference & & Reference & \\
\hline Stage III & 111 & 3.18 (1.12-9.04) & 0.030 & $2.83(1.04-7.68)$ & 0.042 \\
\hline Stage IV & 161 & $6.93(2.61-18.38)$ & $<0.001$ & $6.16(2.43-15.61)$ & $<0.001$ \\
\hline Stage unknown & 1050 & $3.70(1.42-9.61)$ & 0.007 & $3.51(1.42-8.71)$ & 0.007 \\
\hline $\mathrm{HDI}^{2}$ (unit $=0.1$ ) & 1406 & $0.78(0.68-0.89)$ & $<0.001$ & $0.80(0.70-0.91)$ & 0.001 \\
\hline
\end{tabular}

CI Confidence interval, HDI Human Development Index

${ }^{1}$ Adjusted for age at diagnosis, stage at diagnosis and sub-national HDI

${ }^{2}$ Human Development Index (http://hdr.undp.org/en/data and https://globaldatalab.org/)

incorporating data from 12 population-based cancer registries and assesses the influence of age, stage at diagnosis and Human Development Index. We used random sampling for inclusion of cases, although the size of the sampling fractions and accordingly the confidence intervals for our estimates varied between registries. The total sample of 1752 men included $44 \%$ of all patients registered with prostate cancer in the participating registries during the study period.

The survival estimates varied widely between registries and countries, as well as within countries and for Harare (Zimbabwe), between the racial groups. We found a 1-, 3and 5-year observed (all-cause) survival (95\% CI) for all 13 cohorts of prostate cancer patients of $72.1 \%$ (69.6-74.6), $49.2 \%(46.4-52.1)$ and $39.1 \%(36.3-42.2)$, respectively, while the ASRS was at $78.4 \%$ (76.2-80.6), $63.1 \%$ (60.1-66.1) and 60.3\% (56.7-64.1), respectively. The ten countries under observation had an estimated average relative survival (taking into account the different sample sizes from each country) of 55.3 (42.1-73.2) at year 5. Nearly half of the patients with staging information had Stage IV disease. In flexible Poisson regression analysis, we found late stages of prostate cancer associated with increased excess hazards, compared to early stages and a 0.1 increase in the HDI to be associated with a $20 \%$ lower excess hazard of death. We did not find an association between age at diagnosis and the hazard of death in prostate cancer patients. It is possible that the lack of an association between hazard of death and age is due to confounding by stage; although this was adjusted for in the model, the adjustment would be far from complete, given the high proportion of cases with missing stage data.

The poor observed survival is to be expected given the advanced stage and age of prostate cancer patients (mean age
70.5 years in our study). Relative survival provides an estimate of the probability of surviving prostate cancer (excluding death from other causes), while comparisons between different series requires adjustment for age (if survival is related to age). Comparing our results of the ASRS to high income countries, like the US, Germany or the UK, where the 5-year age-standardized net survival in 2010-2014 was estimated to be at 97.4, 91.6 and $88.7 \%$ [14], respectively, we revealed that the average outcome of prostate cancer patients in SSA is rather poor. However, survival from prostate cancer in high income countries was much lower only a few decades ago. For example, in the US, the 5-year relative survival increased from $70 \%$ in the period of 1975-1979, to $99.3 \%$ in $1995-2000$ [35]. In the registry of Kampala (Uganda) the 5-year ASRS for prostate cancer patients was reported to be $46.9 \%$ during 1993-1997[16], while in our study it was at $51.2 \%$. Data from Harare (Zimbabwe) from the same period showed a 3-year RS for black men of $27.1 \%$ and a 5-year survival for white men of $83.7 \%$ [17], respectively. In our study those estimates are at 59.9 and $76.8 \%$, respectively. The survival of cancer patients is a product of a multitude of factors and it is therefore not easy to determine any single reason for the low survival of SSA prostate cancer patients, and for the variations we observe between and within countries. In high income countries, the implementation of routine and opportunistic screening for prostate cancer in asymptomatic men by prostate specific antigen (PSA) testing has been a major factor causing the very high survival currently observed, with much of the longer survival times being a consequence of the so called lead-time bias introduced through over-diagnosis of indolent cancers [36]. In SSA there are no systematic screening programs in place, and there are no data on the prevalence of opportunistic PSA testing. A few studies indicate that PSA screening 
uptake is sparse in SSA [37, 38]. The rising incidence rates all over SSA in a recent trend analysis of population-based cancer registry data is believed to be linked to rising usage of PSA testing [3].

Another factor influencing the survival of prostate cancer patients is the stage at diagnosis. The majority of patients in our cohort were diagnosed at Stage III and Stage IV. This is in line with most (mainly hospital-based) studies from SSA $[9,39,40]$. The proportion of metastatic disease in high income countries is much smaller $(6 \%$ in the USA for example [41]), than in our study, where nearly one in two patients (with known stage) was metastatic. As expected, late stage III and stage IV disease were associated with a higher excess hazard of death, even when adjusting for age and HDI.

It is likely that the high proportion of late stage disease is due to lack of awareness of the disease. Only $54 \%$ of 545 men in a cross-sectional study from Kampala ever heard about prostate cancer [42]. A recent review from Baratedi et al., similarly pointed towards lack of knowledge and a multitude of misconceptions about the disease. This study also identified lower education and socioeconomic status as barriers to prostate cancer screening on the patient level [43]. These factors are also known to influence the outcome of prostate cancer patients in general [44]. Since we had no information on individual socioeconomic status, we adjust for this on registry level using the HDI as covariate, which comprises information on life expectancy, education level and gross per capita income [18, 22]. We found a higher HDI to be associated with a reduction of the excess hazard of death. Since we modeled in a relative survival setting, which already adjusts for the influence of the background population's life expectancy, this association will be mainly driven by the influence of education level and gross per capita income. Regions with a higher gross domestic product are likely to have better health-care systems with better access to early detection and adequate treatment, as well as to post-treatment follow-up. A retrospective hospital-based study from South Africa found that patients wait an average of three months to receive the results of their prostate biopsy and to have their treatment planned [45]. It is estimated that $93 \%$ of the population of SSA have no access to timely, safe and affordable surgery and anesthesia [5]. A reason among others is likely to be that the region has the least surgical workforce worldwide [46].Shortcomings in the access to radiotherapy, as well as problems with the few functioning radiotherapy machines are a well-known problem in low income countries and especially in this region $[4,6,47]$. Yet a study from a tertiary referral center in Ghana showed that even in this setting the provision of adequate radiotherapy is possible and reports high 5-year observed survival rates $(96 \%)$ of non-metastatic patients in their clientele [10].
It is possible also that there is a genetic component to the poor survival of men with prostate cancer in SSA. Men of African ancestry not only have been associated with a higher risk of developing prostate cancer, but also with more aggressive disease [48]. Nevertheless, the socioeconomic factors confounding this association are likely to be the principal reason for the racial survival disparities [49-51].

The differences we saw in 5-year relative survival between age groups, were not observed in our model—even in the multivariable (adjusted) analysis. Possibly the pattern observed in the pooled relative survival analysis is artificially influenced by the large proportion of patients in the oldest age group coming from Mauritius (67 of 181 patients at risk in years 4 and 5). Another reason is that relative survival estimation makes use of national lifetables, in which the mortality rates are too pessimistic for the background mortality of men with prostate cancer in the populations served by the registries. Most are in relatively affluent regions of their countries - the capital cities-which will artificially inflate the estimates of relative survival of our patients. Regionally stratified lifetables would reduce such bias, but are not readily available at the moment.

Stage was unknown for around $60 \%$ of patients from registries contributing stage information. Cancer registrars can only abstract staging information, if they are sufficiently trained, have access to medical records and if, after all, cancer stage had been assessed by physicians and was documented in the record. This problem is being addressed by the development of simplified staging protocols, which can be used by cancer registrars to allocate stage at diagnosis, in the absence of documented stage in the case record [52].

We used the HDI as a registry-level substitute covariate for unavailable patient-level socioeconomic data. Allocating socioeconomic status based on residential-level indices is now a very widely used technique, although it incorporates misclassification at the individual level [53], and, in our study, is also completely confounded with the actual cancer registry.

In order to minimize any potential bias due to incompleteness of registration, we only included AFCRN registries, which are evaluated as registering at least $70 \%$ of their target population [13]. Five of our registries (Eastern Cape, Harare, Kampala, Nairobi, and Seychelles) were included in Cancer Incidence in Five Continents during the relevant period [54]. Several studies have investigated aspects of registration practice to ascertain whether they can explain observed survival differences between countries, finding that particular registration differences are unlikely to impact greatly on survival differences [55]. A large number of patients were lost to follow up (LFU), especially during the first year of follow-up. The Cox-models suggest that LFU at year 1 and during the whole period, was not associated with age or stage and thus was considered to be random. 
We analyzed data from 12 population-based cancer registries from 10 SSA countries, giving insight into the survival experience of prostate cancer patients in the general population. We show that survival of prostate cancer patients in SSA is generally poor, but differs widely between and also within different countries, while late stage disease and a lower Human Development index were associated with a substantially increased risk of death. More studies are needed to evaluate and adjust for the influence of patientlevel socioeconomic factors, treatment and comorbidity. However, we believe that raising awareness of the disease in the general population to mitigate late stage presentation, as well as investments in training and equipment of healthcare systems to improve the patterns of care would lead to a reduction of unnecessary early deaths from a disease that has rather good prognosis in more affluent regions of the world.

\section{Appendix methods}

\section{Modeling of lifetables}

Single year and 5-year-age abridged lifetables for the years 2000-2016 at national level was retrieved from the WHO
Global Health Observatory. We obtained age-specific death rates, calculated from information on deaths among persons in the age group at age $\mathrm{x}$ during a given time period and the total person-years for the population in the same time period. A full description of the methods is available elsewhere: https://www.who.int/healthinfo/statistics/LT_method.pdf? ua $=1$.

The number of deaths and person-time by sex, year and country were used to estimate mortality rates using a Poisson regression and a flexible function to expand the abridged age groups $(0-4,5-9,10-14 \ldots 80+)$ to single ages $(0,1$, $2,3,4,5 \ldots 99)$. Briefly, we used the number of deaths and person-time by year and sex for each country separately. Smoothed age-specific mortality rates were derived using Poisson regression modeling by piecewise and spline function using eight knots with locations at ages $0-10$ (three knots), 15-30 (three knots) and 50-85 + (two knots). The method chosen was fully described and explored by Rachet and colleagues (2015): https://bmcpublichealth.biomedcent ral.com/track/pdf/10.1186/s12889-015-2534-3 (Figs. 3, 4, 5, 6, 7; Tables 4, 5, 6).

Table 4 Registries with potential for 5-year follow-up time

\begin{tabular}{|c|c|c|c|c|c|c|}
\hline \multirow[t]{2}{*}{ Country } & \multirow[t]{2}{*}{ Registry } & \multirow[t]{2}{*}{ Period of diagnosis } & \multirow[t]{2}{*}{$\begin{array}{l}\text { No. of cases included for } \\
\text { survival analyses }\end{array}$} & \multirow[t]{2}{*}{$\begin{array}{l}\text { No. of cases with poten- } \\
\text { tial of 5-year FU }\end{array}$} & \multicolumn{2}{|c|}{$\begin{array}{l}\text { No. of cases with } \\
\text { complete (alive or dead) } \\
\text { 5-year FU (\%) }\end{array}$} \\
\hline & & & & & Alive & Dead \\
\hline Côte d'Ivoire & Abidjan & 2013-2014 & 127 & 47 & $1(2)$ & $25(53)$ \\
\hline Ethiopia & Addis Ababa & 2012 & 45 & $3 *$ & $0(0)$ & $2(67)$ \\
\hline \multirow[t]{2}{*}{ Kenya } & Eldoret & 2009-2013 & 23 & 17 & $4(24)$ & $7(41)$ \\
\hline & Nairobi & 2009-2013 & 134 & 103 & $28(27)$ & $25(24)$ \\
\hline Mauritius & Mauritius & 2005-2009 & 331 & 255 & $115(45)$ & $140(55)$ \\
\hline Namibia & Namibia & 2012-2013 & 35 & 20 & $9(45)$ & $3(15)$ \\
\hline Seychelles & Seychelles & 2008-2013 & 119 & 92 & $29(32)$ & $54(59)$ \\
\hline South Africa & Eastern Cape & 2008-2013 & 201 & 113 & $17(15)$ & $77(68)$ \\
\hline Uganda & Kampala & 2009-2013 & 115 & 103 & $23(22)$ & $51(50)$ \\
\hline \multirow[t]{2}{*}{ Zimbabwe } & Harare (black) & 2009-2013 & 149 & 94 & $34(36)$ & $56(60)$ \\
\hline & Harare (white) & 2009-2013 & 41 & 41 & $16(39)$ & $19(46)$ \\
\hline Total & & & 1320 & 888 & $276(31)$ & $459(52)$ \\
\hline
\end{tabular}

*Since there were only three cases, we did not assess 5-year survival for Addis Ababa (Ethiopia) 
Table 5 Age-specific and age-standardized relative 1-, 3- and 5-year survival by registry

\begin{tabular}{|c|c|c|c|c|c|}
\hline \multirow[t]{2}{*}{ Registry } & \multicolumn{4}{|l|}{ Year $1 \mathrm{RS}$} & \multirow[t]{2}{*}{ Year 1 ASRS } \\
\hline & $<65$ & $65-74$ & $>=75$ & All ages & \\
\hline Abidjan & $83.8(70.8-99.1)$ & 77.7 (64.3-93.9) & $94.8(75.9-118.3)$ & 85 (76.1-95) & $85.2(77.8-93.3)$ \\
\hline Addis Ababa & $76.8(57.1-103.3)$ & $55.8(37.2-83.8)$ & $60.6(36.5-100.5)$ & $63.4(49.8-80.9)$ & $66(55.1-79.1)$ \\
\hline Bulawayo & $25.5(7.1-91.3)$ & $30.6(13.9-67.6)$ & $50(30.7-81.4)$ & $40.4(26.6-61.5)$ & $34.1(22.7-51.1)$ \\
\hline Cotonou & $78(54.7-111.2)$ & $63.2(40.1-99.7)$ & 110.7 (86.7-141.5) & $80.4(63.8-101.2)$ & $83.2(70.9-97.7)$ \\
\hline Eastern Cape & $63.7(50.2-80.8)$ & $68.7(56.7-83.2)$ & $68.5(57-82.4)$ & $67.4(59.9-75.7)$ & $66.5(60.1-73.6)$ \\
\hline Eldoret & $51.3(19.3-136.7)$ & $93.1(74.9-115.8)$ & $102.4(102.4-102.4)$ & $99.7(85.1-116.8)$ & $78.3(62.3-98.4)$ \\
\hline Harare (black) & $67.1(51.1-88.2)$ & $74(63.6-86.1)$ & $67.2(53.9-83.7)$ & $70.8(63.1-79.6)$ & $69.1(61.9-77.3)$ \\
\hline Harare (white) & $100.7(100.7-100.7)$ & 70.7 (50.3-99.3) & $79.6(60.2-105.1)$ & $78.3(64.6-95)$ & 85.9 (78.5-94) \\
\hline Kampala & $75.6(61.5-93)$ & $65.7(51.4-84)$ & $69.2(52-92.1)$ & $69.7(60.4-80.5)$ & $70.9(63.2-79.4)$ \\
\hline Mauritius & 82.7 (73.9-92.6) & 85.7 (78.6-93.5) & $82.6(74.9-91.2)$ & $84.3(79.6-89.3)$ & $83.6(79.5-87.8)$ \\
\hline Nairobi & $91(82.5-100.5)$ & 76.7 (62.7-93.9) & $91.1(76.7-108.2)$ & $86.8(79.5-94.9)$ & $86.9(81-93.2)$ \\
\hline Namibia & $88.6(73.2-107.3)$ & $92(74-114.3)$ & $83.4(57.5-121)$ & 88.7 (76.7-102.6) & $88.1(78.2-99.2)$ \\
\hline Seychelles & $87.4(75.8-100.9)$ & 88 (77.7-99.6) & $83.9(72-97.9)$ & $86.6(79.7-94.1)$ & 86.6 (80.9-92.6) \\
\hline Total & 79.5 (74.9-84.3) & 75.9 (71.8-80.3) & $79.2(74.5-84.2)$ & $78(75.4-80.7)$ & $78.4(76.2-80.6)$ \\
\hline \multirow[t]{2}{*}{ Registry } & \multicolumn{4}{|l|}{ Year 3 RS } & \multirow[t]{2}{*}{ Year 3 ASRS } \\
\hline & $<65$ & $65-74$ & $>=75$ & All ages & \\
\hline Abidjan & $36.8(21.6-62.5)$ & $48.7(32.3-73.4)$ & $83.8(48.7-144.3)$ & $51.5(38.6-68.8)$ & $53.9(41.9-69.3)$ \\
\hline Addis Ababa & $47(24.3-90.9)$ & $33.9(17.2-66.7)$ & $28.1(9.5-83.4)$ & $35(21.1-58.1)$ & $37.7(26-54.6)$ \\
\hline Bulawayo & - & $33.6(15.2-74.3)$ & - & $15.4(5.8-41.1)$ & - \\
\hline Cotonou & $41.1(19.7-85.7)$ & - & $72(28.2-183.9)$ & $37.2(18.6-74.3)$ & - \\
\hline Eastern Cape & $45.8(30.5-68.8)$ & $53.9(39.1-74.1)$ & $53.8(38.4-75.3)$ & $51.5(41.8-63.4)$ & $50.5(42.5-59.9)$ \\
\hline Eldoret & - & $82(57.5-116.9)$ & $47.6(17.5-129.9)$ & $60.1(37.2-96.9)$ & - \\
\hline Harare (black) & $59.3(42.8-82.2)$ & $46.1(34.5-61.5)$ & $78.6(61.3-100.8)$ & $59.9(50.5-70.9)$ & $61.1(53-70.4)$ \\
\hline Harare (white) & $81.2(49.7-132.5)$ & $70.2(46.9-105.1)$ & $85.9(60.8-121.4)$ & $79.7(62.2-102.1)$ & 79.4 (64.3-98) \\
\hline Kampala & $60(43.9-82.1)$ & $48.5(33.1-71.2)$ & $48.1(28.8-80.6)$ & $52.7(41.8-66.4)$ & $53.2(44.3-64)$ \\
\hline Mauritius & $68.9(58.1-81.7)$ & $68.3(58.8-79.4)$ & $73(61.5-86.7)$ & $71.1(64.6-78.4)$ & $69.9(64.6-75.7)$ \\
\hline Nairobi & $77.1(63.6-93.6)$ & $64.3(47.4-87.1)$ & $117.6(99-139.6)$ & $82(71.5-94)$ & $85.1(77.1-94)$ \\
\hline Namibia & $85.4(66.4-109.9)$ & $84(58.9-119.8)$ & $55.7(24.5-126.4)$ & $81.7(65-102.8)$ & 76.4 (62.9-92.8) \\
\hline Seychelles & 70.9 (54.8-91.8) & $67.1(52.5-85.9)$ & 73.4 (55.7-96.8) & $70.7(60.7-82.5)$ & $70.6(62.3-79.9)$ \\
\hline Total & $61.8(56-68.2)$ & $57.7(52.5-63.5)$ & $70.2(63.2-77.9)$ & $62.9(59.4-66.7)$ & $63.1(60.1-66.1)$ \\
\hline \multirow[t]{2}{*}{ Registry } & \multicolumn{4}{|l|}{ Year 5 RS } & \multirow[t]{2}{*}{ Year 5 ASRS } \\
\hline & $<65$ & $65-74$ & $>=75$ & All ages & \\
\hline Abidjan & - & - & $76.3(31.3-186.2)$ & 55 (38.9-77.7) & - \\
\hline Eastern Cape & $41.6(24.7-70)$ & $50.9(34.1-76)$ & $48.1(30.7-75.3)$ & $48.2(36.6-63.4)$ & $46.2(37-57.6)$ \\
\hline Eldoret & - & $68.1(36.6-126.9)$ & $47.6(17.5-129.9)$ & $75.6(41.3-138.6)$ & - \\
\hline Harare (black) & $49.3(31.7-76.8)$ & $38.9(27-56)$ & $84.3(59.8-118.8)$ & $54.3(43.5-67.9)$ & $56.4(46.7-68.2)$ \\
\hline Harare (white) & $81.2(49.7-132.5)$ & $52.4(27.4-100.5)$ & $90.6(59.4-138.3)$ & 76.8 (55.6-106.0) & $75.6(59.4-96.2)$ \\
\hline Kampala & $58.3(41.5-81.8)$ & $39.8(24.3-65.3)$ & $52.4(27.4-100.1)$ & $49.3(37.5-64.8)$ & $51.2(40.9-64.1)$ \\
\hline Mauritius & $63.5(51.7-77.9)$ & $68.6(57.3-82.2)$ & 75 (60-93.9) & $70.0(62.1-79.0)$ & $68.3(62-75.3)$ \\
\hline Nairobi & $65.7(49.8-86.7)$ & $60.7(39.8-92.8)$ & $152.6(121.4-191.8)$ & $80.7(66.9-97.5)$ & $89.5(78.2-102.3)$ \\
\hline Namibia & $90.8(70.6-116.8)$ & $88.9(54.9-144.1)$ & $55.7(24.5-126.4)$ & $88.4(68.4-114.3)$ & 80.1 (64.9-98.7) \\
\hline Seychelles & $55(37.6-80.3)$ & $54.6(37.1-80.4)$ & $71.4(49.1-103.8)$ & $59.4(47.4-74.4)$ & $59.6(49.8-71.4)$ \\
\hline Total & $56.1(49.8-63.2)$ & $51.8(45.7-58.7)$ & $74.9(65.3-85.9)$ & $60(55.7-64.6)$ & $60.3(56.7-64.1)$ \\
\hline
\end{tabular}

$A S R S$ age-standardized relative survival, $R S$ relative survival 


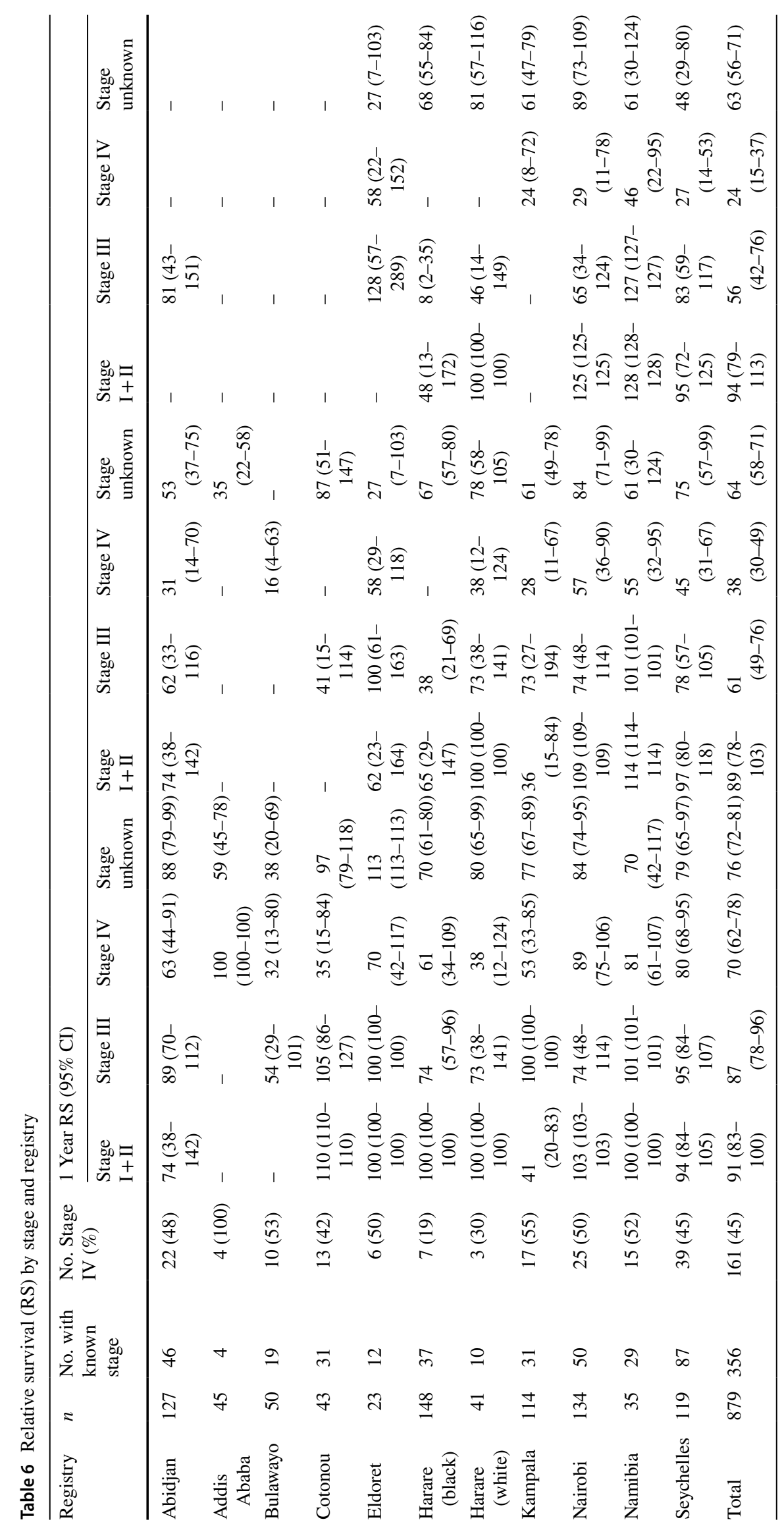


Fig. 3 Process of patient followup. ${ }^{1}$ 31st December, 2017, (for Mauritius: 31st December, 2013)

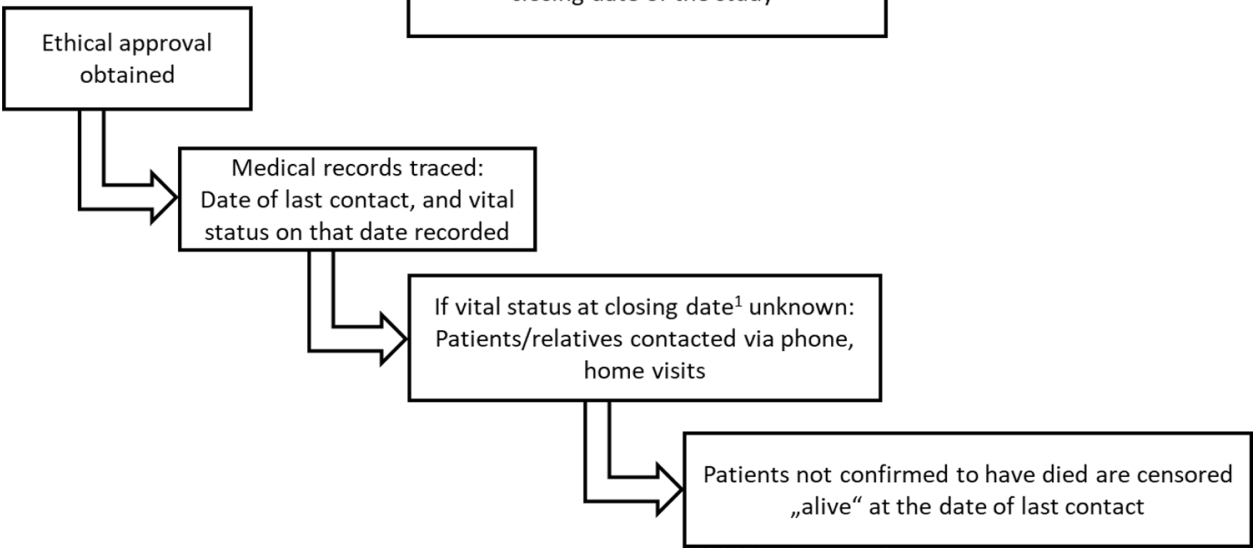

OBJECTIVE : To obtain information on vital status of subjects on the closing date of the study ${ }^{1}$

Number of patients by age at diagnosis and by registry
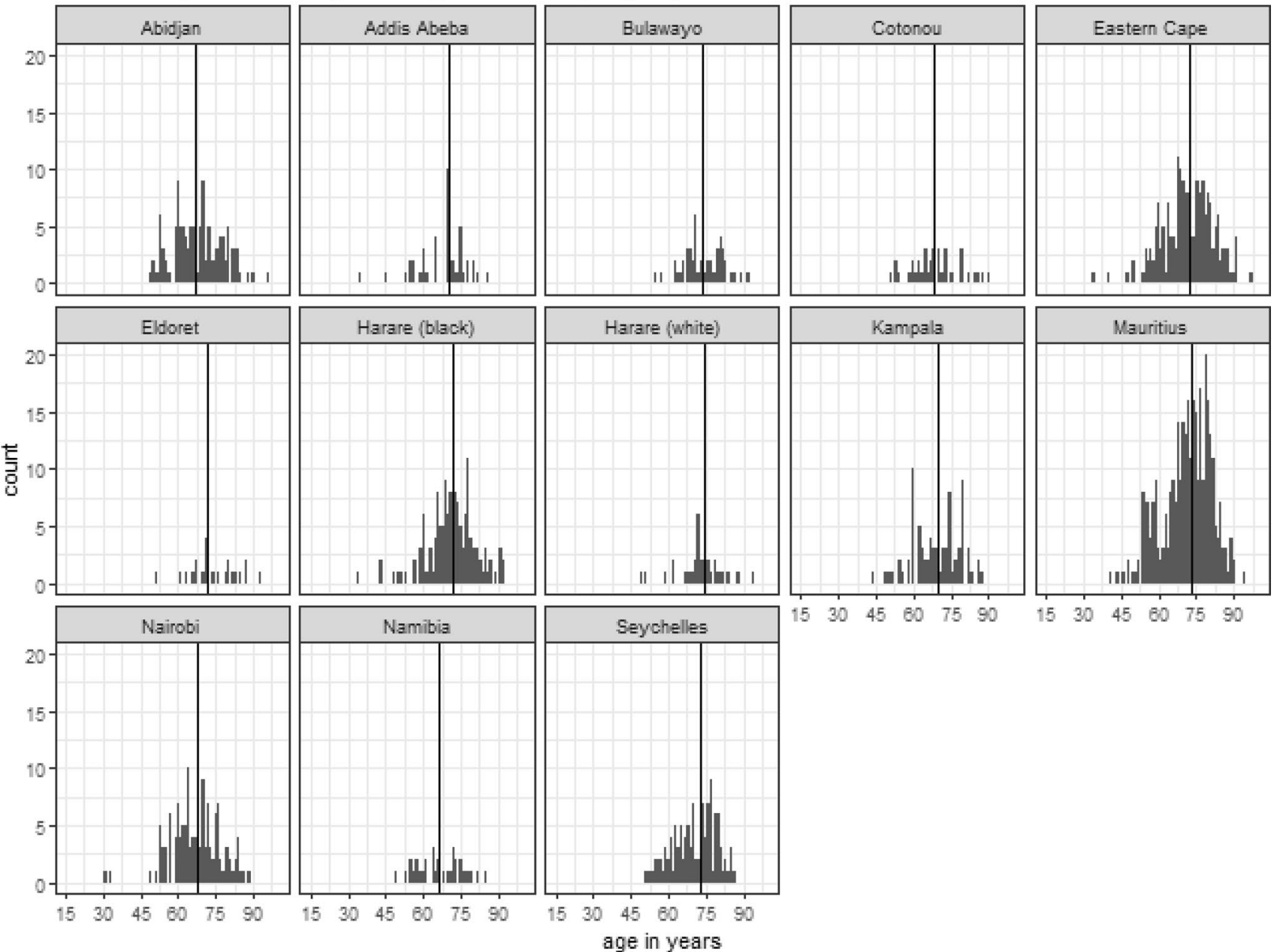

Fig. 4 Number of patients by age at diagnosis in years, by registry; black vertical lines indicate median age per registry 
Number of patients by stage and by registry

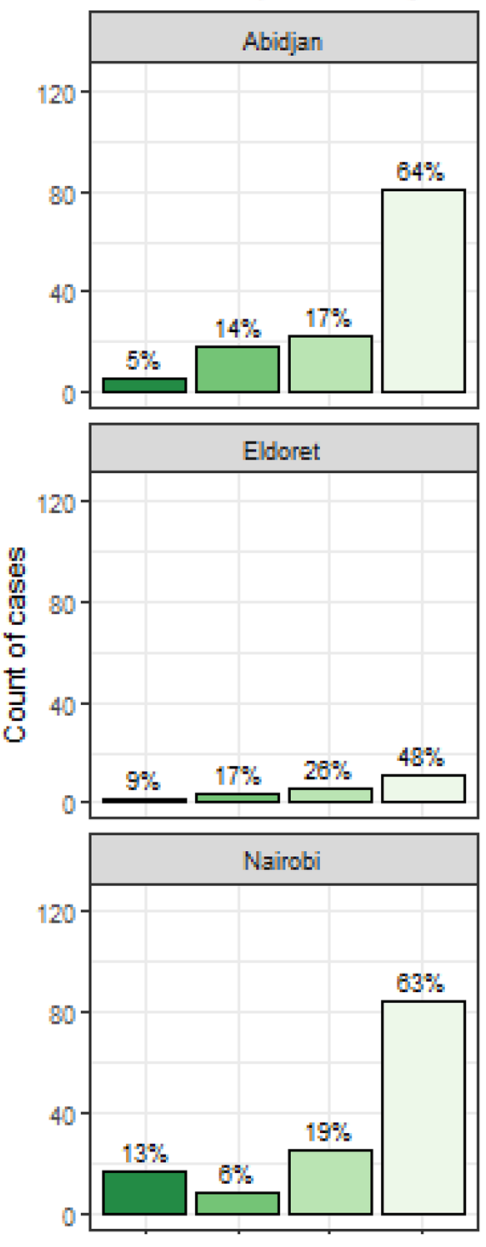

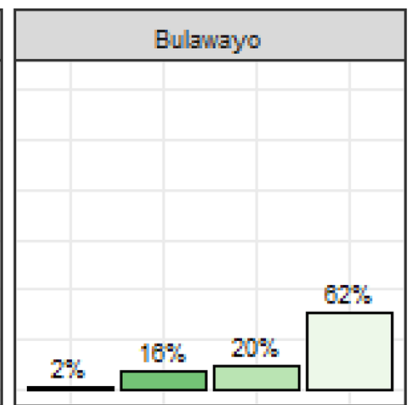
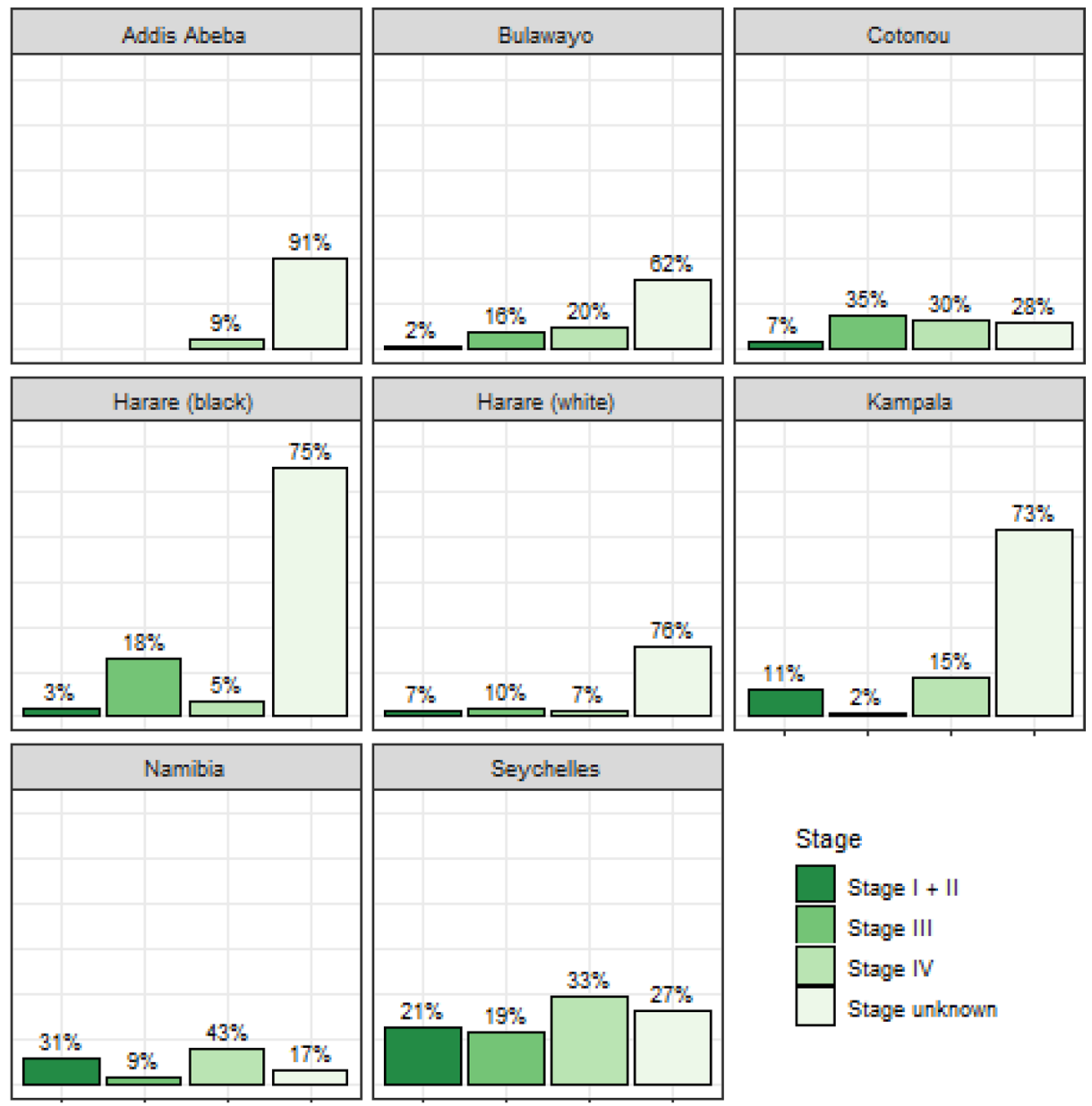

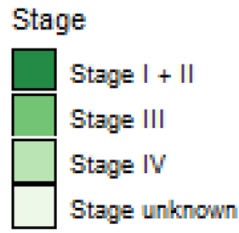

Stage

Fig. 5 Distribution of stage by registry (Mauritius and Eastern Cape (South Africa) excluded) 


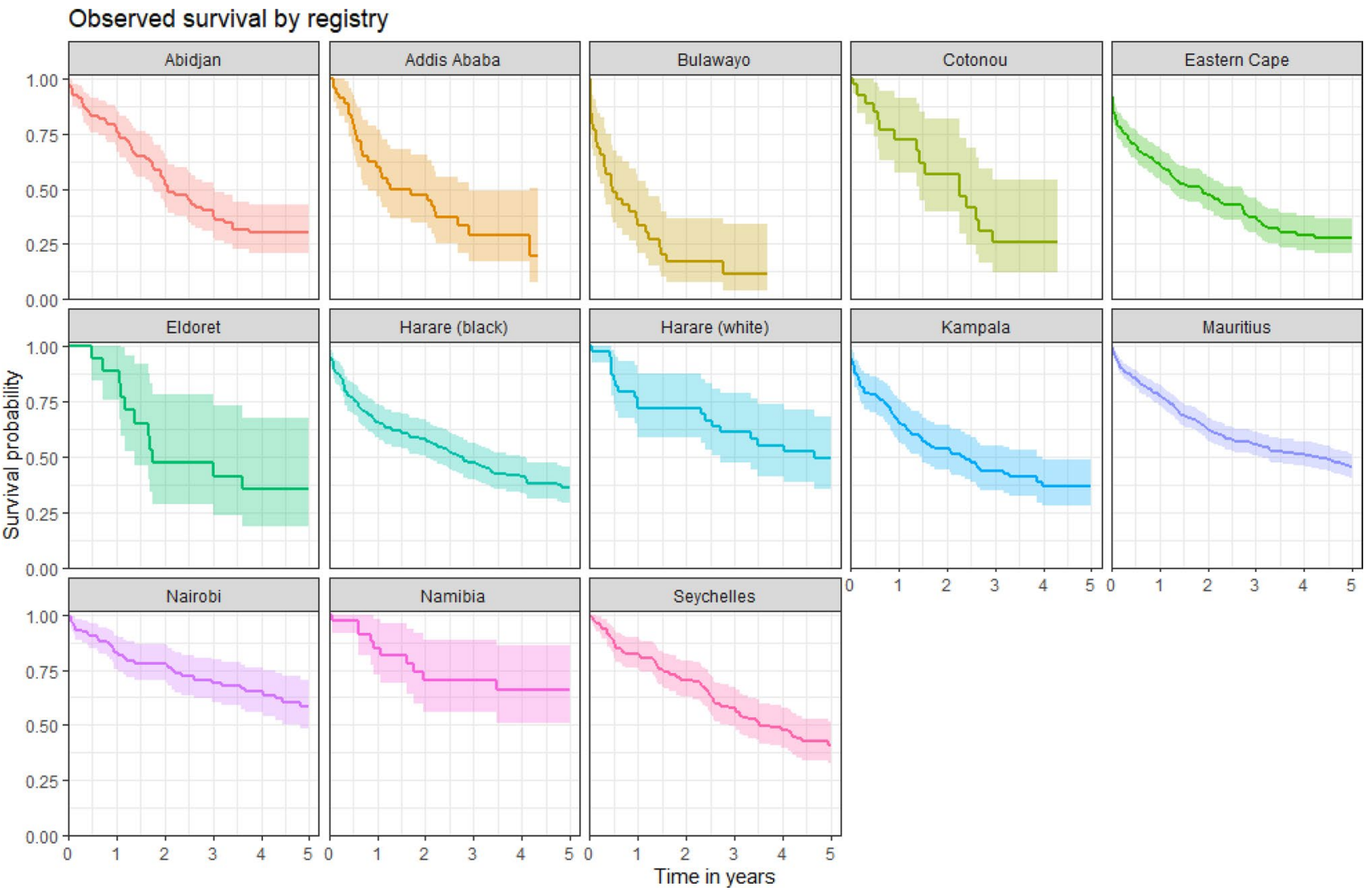

Fig. 6 Kaplan-Meier overall survival probabilities (95\% confidence intervals) by registry 


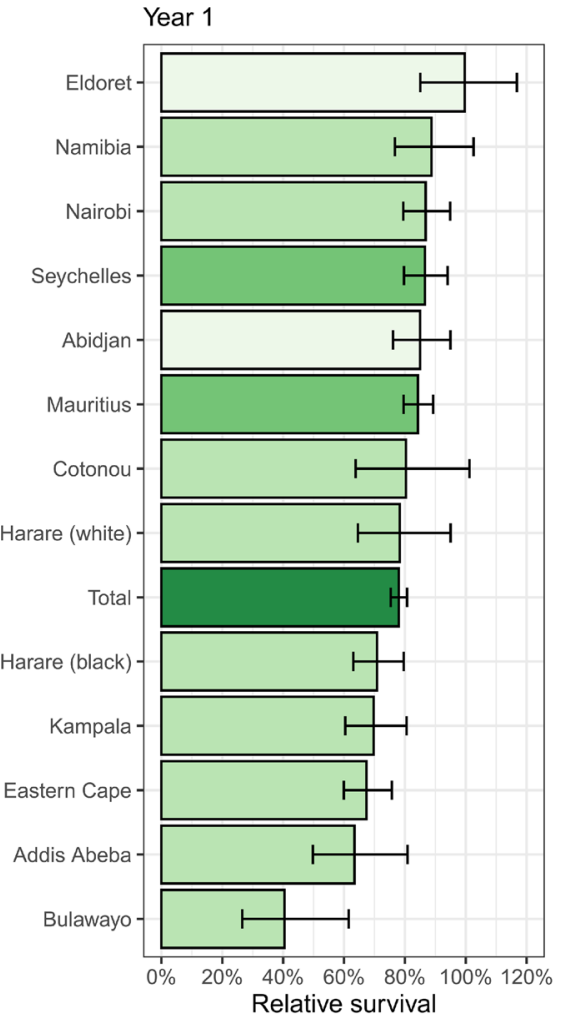

HDI Level:
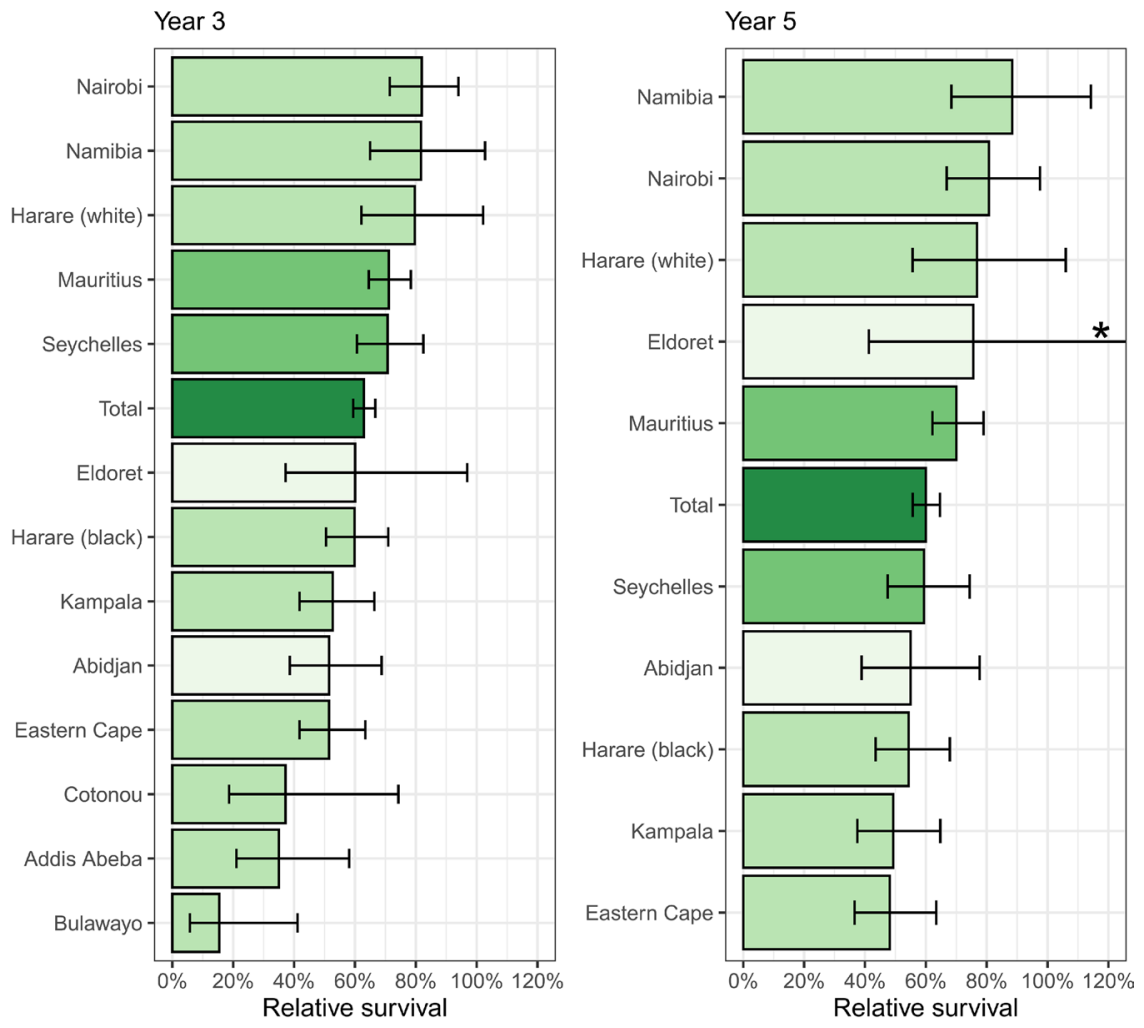

Fig. 7 1-, 3- and 5-year relative survival with 95\% confidence intervals (CI) by registry and Human Development Index (HDI); *The upper limit of Eldoret's $95 \% \mathrm{CI}$ is at $164 \%$

Acknowledgments We gratefully acknowledge the work of the staff of all the contributing registries of the African Cancer Registry Network. Additionally, we gratefully acknowledge the support from Prof. Dr. Stephan Feller, coordinator and PI of the Halle-Oxford exchange fellowship grant within the EU/ESF-funded research "International Research Network biology of disease and molecular medicine" ZS/2016/08/80642 at Martin-Luther-University Halle-Wittenberg.

Author contributions T. P. S., E. J. K. and D. M. P. had full access to all the data in the study and take responsibility for the integrity of the data and the accuracy of the data analysis. Study concept and design: Parkin, Joko-Fru, Seraphin; Acquisition of data: S., P., L., M., C., S., K., N., F., W., A., G., H., B.; Analysis and interpretation of data: S., P., J.-F., K.; Drafting of the manuscript: S., P., K.; Critical revision of the manuscript for important intellectual content: S., P., K., J.-F., M., C., S., K., N., F., W., A., G., H., B.; Administrative, technical, or material support: L.; Study supervision: P., K.

Funding Tobias P. Seraphin was recipient of a 7-month Halle-Oxford exchange fellowship grant within the EU/ESF-funded research „International Research Network biology of disease and molecular medicine" ZS/2016/08/80642 from Martin-Luther-University Halle-Wittenberg. International Agency for Research on Cancer and American Cancer Society provided financial support for the extra data collection activities. The Commonwealth Scholarship, funded by the UK Government, is funding W. Yvonne Joko-Fru's PhD study at the University of Oxford. Open Access funding enabled and organized by Projekt DEAL.
Data accessibility The data that support the findings of this study are available from the corresponding author upon reasonable request, which will be evaluated by the AFCRN research committee. Details of the data application process are outlined on the AFRCN website (http:/afcrn. org/index.php/research/how-to-apply/76-research-collaborations).

Code availability The custom code used around the packages described in the methods section is available from the corresponding author upon reasonable request.

\section{Declarations}

Conflict of interest The authors declare no potential conflicts of interest.

Ethical statement The AFCRN research committee approved this study (July 2019), as well as the respective registries. We conducted the study in accordance to the Declaration of Helsinki. The study used routinely collected, anonymised data, therefore no special ethical approval was needed.

Open Access This article is licensed under a Creative Commons Attribution 4.0 International License, which permits use, sharing, adaptation, distribution and reproduction in any medium or format, as long as you give appropriate credit to the original author(s) and the source, provide a link to the Creative Commons licence, and indicate if changes were made. The images or other third party material in this article are included in the article's Creative Commons licence, unless indicated 
otherwise in a credit line to the material. If material is not included in the article's Creative Commons licence and your intended use is not permitted by statutory regulation or exceeds the permitted use, you will need to obtain permission directly from the copyright holder. To view a copy of this licence, visit http://creativecommons.org/licenses/by/4.0/.

\section{References}

1. Ferlay J, Colombet M, Soerjomataram I et al (2018) Global cancer observatory: cancer today. International Agency for Research on Cancer, Lyon, France. https://gco.iarc.fr/Today. Accessed 4 Aug 2020

2. Ferlay J, Ervik MJ, Lam F et al (2018) Global cancer observatory: cancer tomorrow. International Agency for Research on Cancer, Lyon, France. https://gco.iarc.fr/tomorrow. Accessed 4 Aug 2020

3. Seraphin TP, Joko-Fru WY, Kamaté B et al (2021) Rising prostate cancer incidence in Sub-Saharan Africa: a trend analysis of data from the African cancer registry network. Cancer Epidemiol Biomarkers Prev 30:158-165. https://doi.org/10.1158/ 1055-9965.EPI-20-1005

4. Atun R, Jaffray DA, Barton MB et al (2015) Expanding global access to radiotherapy. Lancet Oncol 16:1153-1186. https://doi. org/10.1016/S1470-2045(15)00222-3

5. Meara JG, Leather AJM, Hagander L et al (2015) Global Surgery 2030: evidence and solutions for achieving health, welfare, and economic development. Lancet 386:569-624. https://doi. org/10.1016/S0140-6736(15)60160-X

6. Abdel-Wahab M, Bourque JM, Pynda Y et al (2013) Status of radiotherapy resources in Africa: an international atomic energy agency analysis. Lancet Oncol 14:e168-e175. https://doi.org/10. 1016/S1470-2045(12)70532-6

7. Yamoah K, Beecham K, Hegarty SE et al (2013) Early results of prostate cancer radiation therapy: an analysis with emphasis on research strategies to improve treatment delivery and outcomes. BMC Cancer 13:23. https://doi.org/10.1186/1471-2407-13-23

8. Badmus TA, Adesunkanmi A-RK, Yusuf BM et al (2010) Burden of prostate cancer in southwestern Nigeria. Urology 76:412-416. https://doi.org/10.1016/j.urology.2010.03.020

9. Cassell A, Yunusa B, Jalloh M et al (2019) A review of localized prostate cancer: an African perspective. World J Oncol 10:162-168

10. Asamoah FA, Yarney J, Awasthi S et al (2018) Contemporary radiation treatment of prostate cancer in Africa: a Ghanaian experience. J Glob Oncol 4:1-13. https://doi.org/10.1200/JGO. 17.00234

11. Magoha GA (2000) Management and survival in advanced prostate cancer in Nairobi. East Afr Med J 77:260-263. https://doi. org/10.4314/eamj.v77i5.46630

12. Parkin DM (2006) The evolution of the population-based cancer registry. Nat Rev Cancer 6:603-612

13. (2020) African Cancer Registry Network. https://afcrn.org/ index.php/about-us. Accessed 9 Apr 2020

14. Allemani C, Matsuda T, Di Carlo V et al (2018) Global surveillance of trends in cancer survival 2000-14 (CONCORD-3): analysis of individual records for 37513025 patients diagnosed with one of 18 cancers from 322 population-based registries in 71 countries. Lancet 391:1023-1075. https://doi.org/10.1016/ S0140-6736(17)33326-3

15. Sankaranarayanan R, Swaminathan R (2011) Cancer survival in Africa, Asia, the Caribbean and Central America. World Health Organization
16. Gondos A, Brenner H, Wabinga H, Parkin DM (2005) Cancer survival in Kampala, Uganda. Br J Cancer 92:1808-1812. https://doi.org/10.1038/sj.bjc.6602540

17. Gondos A, Chokunonga E, Brenner H et al (2004) Cancer survival in a southern African urban population. Int J Cancer 112:860-864. https://doi.org/10.1002/ijc.20471

18. Smits J, Permanyer I (2019) Data descriptor: the subnational human development database. Sci Data 6:1-15. https://doi.org/ 10.1038 /sdata.2019.38

19. World Bank Group (2020) Completeness of death registration with cause-of-death information. https://data.worldbank.org/indicator/ SP.REG.DTHS.ZS?locations=MU. Accessed 6 Aug 2020

20. Amin MB, Edge S, Greene F et al (2017) AJCC cancer staging manual, 8th edn. Springer International Publishing, New York

21. Fritz A, Percy C, Jack A, et al (2013) Basis of diagnosis. In: international classification of diseases for oncology (ICD-O)- 3rd edn. World Health Organization, Geneva

22. (2019) Human development report 2019 : beyond income, beyond averages, beyond today: inequalities in human development in the 21 st century. United Nations Development Programme, New York

23. Brenner H, Swaminathan R (2011) Statistical methods for cancer survival analysis. In: Sankaranarayanan R, Swaminathan R, Lucas E (eds) Cancer survival in Africa, Asia, the Caribbean and Central America (SurvCan), IARC scientific publications, International Agency for Research on Cancer, World Health Organization. Lyon, France

24. R Core Team (2019) R: A language and environment for statistical computing. R Foundation for Statistical Computing, Vienna, Austria. https://www.R-project.org/

25. RStudio Team (2020) RStudio: integrated development for R. RStudio, PBC, Boston, MA. http://www.rstudio.com/

26. Therneau TM, Grambsch PM (2000) Modeling survival data: extending the Cox model. Springer, New York

27. Kassambara A, Kosinski M, Biecek P (2019) Survminer: drawing survival curves using 'ggplot2'. https://rpkgs.datanovia.com/ survminer/index.html

28. Bray F, Parkin DM (2009) Evaluation of data quality in the cancer registry: principles and methods. Part I: comparability, validity and timeliness. Eur J Cancer 45:747-755. https://doi.org/10. 1016/j.ejca.2008.11.032

29. Perme MP, Pavlič K (2018) Nonparametric relative survival analysis with the R package relsurv. J Stat Softw 87(8):1-27. https:// doi.org/10.18637/jss.v087.i08

30. World Health Institution Global Health Observatory (GHO) data. In: life tables. https://www.who.int/gho/mortality_burden_disea se/life_tables/life_tables/en/

31. Lambert P (2008) RCSGEN: Stata module to generate restricted cubic splines and their derivatives. Statistical Software Components S456986, Boston College Department of Economics, revised 15 Sep 2015

32. Corazziari I, Quinn M, Capocaccia R (2004) Standard cancer patient population for age standardising survival ratios. Eur $\mathrm{J}$ Cancer 40:2307-2316. https://doi.org/10.1016/j.ejca.2004.07.002

33. Abdel-Rahman M, Stockton D, Rachet B et al (2009) What if cancer survival in Britain were the same as in Europe: how many deaths are avoidable? Br J Cancer 101(Suppl):S115-S124. https:// doi.org/10.1038/sj.bjc.6605401

34. Dickman PW, Coviello E (2015) Estimating and modeling relative survival. Stata J Promot Commun Stat Stata 15:186-215. https:// doi.org/10.1177/1536867X1501500112

35. Jemal A, Clegg LX, Ward E et al (2004) Annual report to the nation on the status of cancer, 1975-2001, with a special feature regarding survival. Cancer 101:3-27. https://doi.org/10.1002/cncr. 20288 
36. Potosky AL, Miller BA, Albertsen PC, Kramer BS (1995) The role of increasing detection in the rising incidence of prostate cancer. JAMA 273:548-552. https://doi.org/10.1001/jama.1995. 03520310046028

37. Rebbeck TR, Zeigler-Johnson CM, Heyns CF, Gueye SM (2011) Prostate cancer screening, detection and treatment practices, among Sub-Saharan African urologists. African J Urol 17:85-91. https://doi.org/10.1007/s12301-011-0016-0

38. Ojewola RW, Oridota ES, Balogun OS et al (2017) Knowledge, attitudes and screening practices regarding prostatic diseases among men older than 40 years: a population-based study in Southwest Nigeria. Pan Afr Med J 27:151

39. Jalloh M, Niang L, Ndoye M et al (2013) Prostate Cancer in Sub Saharan Africa. J Nephrol Urol Res 1:15-20

40. Rebbeck TR, Devesa SS, Chang B-L et al (2013) Global patterns of prostate cancer incidence, aggressiveness, and mortality in men of African descent. Prostate Cancer 2013:1-12. https://doi.org/10. 1155/2013/560857

41. Surveillance, Epidemiology, and End Results Program S (2020) SEER cancer stat facts: prostate cancer. https://seer.cancer.gov/ statfacts/html/prost.html

42. Nakandi H, Kirabo M, Semugabo C et al (2013) Knowledge, attitudes and practices of Ugandan men regarding prostate cancer. African J Urol 19:165-170. https://doi.org/10.1016/j.afju.2013. 08.001

43. Baratedi WM, Tshiamo WB, Mogobe KD, McFarland DM (2020) Barriers to prostate cancer screening by men in sub-Saharan Africa: an integrated review. J Nurs Scholarsh 52:85-94. https:// doi.org/10.1111/jnu.12529

44. Coughlin SS (2019) A review of social determinants of prostate cancer risk, stage, and survival. Prostate Int 8:49-54. https://doi. org/10.1016/j.prnil.2019.08.001

45. Singh K, Abdel Goad EH, Ramklass SS (2015) Waiting times for prostate cancer diagnosis in KwaZulu-Natal. South Africa South African Med J 105:484. https://doi.org/10.7196/SAMJ.9192

46. Holmer H, Lantz A, Kunjumen T et al (2015) Global distribution of surgeons, anaesthesiologists, and obstetricians. Lancet Glob Heal 3:S9-S11. https://doi.org/10.1016/S2214-109X(14)70349-3
47. Zubizarreta E, Van Dyk J, Lievens Y (2017) Analysis of global radiotherapy needs and costs by geographic region and income level. Clin Oncol 29:84-92. https://doi.org/10.1016/j.clon.2016. 11.011

48. McGinley KF, Tay KJ, Moul JW (2016) Prostate cancer in men of African origin. Nat Rev Urol 13:99-107. https://doi.org/10.1038/ nrurol.2015.298

49. Chornokur G, Dalton K, Borysova ME, Kumar NB (2011) Disparities at presentation, diagnosis, treatment, and survival in African American men, affected by prostate cancer. Prostate 71:985-997. https://doi.org/10.1002/pros.21314

50. Krimphove MJ, Cole AP, Fletcher SA et al (2019) Evaluation of the contribution of demographics, access to health care, treatment, and tumor characteristics to racial differences in survival of advanced prostate cancer. Prostate Cancer Prostatic Dis 22:125136. https://doi.org/10.1038/s41391-018-0083-4

51. DeRouen MC, Schupp CW, Koo J et al (2018) Impact of individual and neighborhood factors on disparities in prostate cancer survival. Cancer Epidemiol 53:1-11. https://doi.org/10.1016/j. canep.2018.01.003

52. Piñeros M, Parkin DM, Ward K et al (2019) Essential TNM: a registry tool to reduce gaps in cancer staging information. Lancet Oncol 20:e103-e111. https://doi.org/10.1016/S1470-2045(18) 30897-0

53. Bryere J, Pornet C, Copin N et al (2017) Assessment of the ecological bias of seven aggregate social deprivation indices. BMC Public Health 17:86. https://doi.org/10.1186/s12889-016-4007-8

54. Wong MCS, Goggins WB, Wang HHX et al (2016) global incidence and mortality for prostate cancer: analysis of temporal patterns and trends in 36 countries. Eur Urol 70:862-874. https://doi. org/10.1016/j.eururo.2016.05.043

55. Rutherford MJ, Møller H, Lambert PC (2013) A comprehensive assessment of the impact of errors in the cancer registration process on 1- and 5-year relative survival estimates. Br J Cancer 108:691-698. https://doi.org/10.1038/bjc.2013.12

Publisher's Note Springer Nature remains neutral with regard to jurisdictional claims in published maps and institutional affiliations. 